\title{
Research on Optimal Allocation of Regional Annual Water Consumption
}

\author{
Xianqi Zhang*
}

School of Water Resources, North China University of Water Resources and Electric Power, Zhengzhou, China

\begin{abstract}
The optimization of regional water distribution refers to distributing regional and industrial water supply scientifically on the premises of limited regional water supply with an excess of demand for the purpose of fulfilling every industry's water supply. The study treats the optimal distribution of annual regional water consumption as a systematic dynamic optimization and analyzes its optimizing process, procedure and basic form of its models. The study constructs a regional water consumption system and raises a model to optimize regional water allocation that focuses on the water consumption standard of many categories, including living water, farm irrigation, forestry, animal husbandry, fishery livestock, industry, the public and environmental water demand of the city. Aiming at achieving the maximum comprehensive benefits of regional water consumption when dealing with its structure and habits, the optimal distribution model of regional water is devised after adopting the dynamic optimized distribution method to optimize the regional water consumption. As is shown by the research result, when applied to the regional water distribution optimization, this model can well optimize the distribution in every region and industry. It can thus coordinate among every system of water demand and supply in every region. This project study is significantly meaningful to ensure the scientific and reasonable water use in a region. It is also crucial to the sustainable utilization of water and sustainable development of society.
\end{abstract}

Keywords: Distribution, model, optimization, water consumption.

\section{INTRODUCTION}

Water resources are fundamental to people's survival and development. With the fast increase of world population and the rapid development of social economy, the gross water requirement soars greatly. It is necessary to seek a scientific method to distribute water, so that we can ensure the regional balanced operation between complex social economic water demand and supply [1, 2]. The aim of the research study is to find a solution that can optimize the allocation of water supply as well as to fulfill the water demand with the assigned gross water supply, therefore achieving maximum benefits [2, 3]. A lot of domestic and international experts and scholars have done researches and discussions in the field of optimal allocation of water [5-10]. With maximum production, delivery capacity and the prediction of demand as the constraints, D. Pearson used many reservoir control curves and the quadratic programming method to study on the issue of water distribution in the Nawwa area in Britain. Professor Hua Shiqian applied the system engineering approach to distributing water supply in the Beijing area. Feng Yaolong and others analyzed the principle of sustainabledevelopment-oriented distribution of regional water supply and established a multi-aim model of water distribution for sustainable development. Weng Wenbin and others combined macroeconomics, system approach and the practice of regional water planning to compose the optimal water distribution theory based on macroeconomics. With

*Address correspondence to this author at the College of Water Resources, Faculty of North China University of Water Resources and Electric Power, Zhenzhou, China; Tel: +86-371-6912-7406; E-mails: zxqi@163.com the guidance of this theory, he came up with the multistage, multi-aim and group-decision method and brought about the result of dynamic integration of water allocation and regional economic system, which was also a breakthrough among the researching approaches of optimal water distribution [11]. Based on the gross water supply level and constrained by the approved gross water supply, the annual regional water plan is devised in accordance with the society's requirement of reasonable and scientific water usage so as to keep the balance across all categories and industries [12]. When the annual water demand plan is in excess of limited water use or the available water supply, it should be reduced under certain rules and standards. The most common way of doing this is to reduce the water demand proportionate to its percentage in all the demands. This method is simple and easy to operate while it also has its disadvantage of lacking enough evidence and science. It may also fail due to ignorance of every industry's characteristics and benefits of water use. The case study raises a dynamic optimal distribution approach to optimize water distribution in all industries while the total water use is limited.

\section{DYNAMIC OPTIMIZATION PROCESS AND MODEL}

Optimal allocation of water resources is usually connected with optimal regulation of water amount and appropriate allocation, etc. Such problems are often generalized into multistep decision process. The so-called multistep decision process refers to the practice of separating research problems into various mutually related stages for which decisions are made correspondingly in order to optimize the entire process, whereas dynamic optimization is 
mainly applied to providing solutions to optimized questions, which may require for more than one solution, with each having its own mathematical value. Therefore dynamic optimization is to find out the most optimized (maximal or minimal) value $[13,14]$. When a solution has several optimal values, usually only one is selected. Such decisions are made on the premise that no aftereffects should occur, i.e. solutions to later sub-problems would not be affected whatever choices are made. During the solution, such practice is determined to achieve optimal solution to the overall problem by solving the partial, sub-problems. The key to dynamic optimization is to save and provide the solution to repeating sub-problems during their first time of appearance, so that solutions won't be repeated when they appear for a second time or more $[14,15]$.

\subsection{Dynamic Optimization Process:}

As a matter of fact, dynamic optimization is a multistep decision process, which consists of stages, status, decisions and strategies $[8,16]$.

(1) Stages: Represent the periods or procedures of the research target during its development. The stages are marked by stage variables, i.e. $i=1,2, \cdots, N$, of which $N$ represents the stage sum.

(2) States: Refers to liable conditions at certain stage during the development of the system. Variables describing states of the system are known as state variables, usually represented by $S$. A stage state consists of both original state and end state, with the modal state of the former stage serving as the original state of the latter stage. If stage $i$ has several $S_{i j}(j=1,2, \cdots, m)$ states numbered as $m$, its state set is marked as $S_{i}=\left\{s_{i 1}, s_{i 2}, \cdots, s_{i m}\right\}$.

(3) Decisions: Refers to the decisions made during the transformation from one state to the next when the former stage state is settled. Decision is marked by decision variables, for example, $d_{i}\left(s_{i}\right)$ is used to represent the decision made during stage $i$ of state $s_{i}$. There might be several viable decisions under one single state, yet decision variables are limited to one certain range, marked as $d_{i}\left(s_{i}\right) \in D_{i}\left(s_{i}\right)$, of which $D_{i}\left(s_{i}\right)$ is referred to as the allowed decision set of state $S_{i}$.

At one certain stage of multistep decision process, when system state $S_{i}$ is set and decision $d_{i}$ is made accordingly, the systematic state then transfers to the next state $S_{i+1}$. Transfer of systematic state is represented by the state transfer equation:

$S_{i+1}=T_{i}\left(s_{i}, d_{i}\right), i=1,2, \cdots, N$

Where, $T_{i}$ is the transfer function of the state.

State transfer equation shows that state $S_{i+1}$ of stage $i+1$ is determined by state $S_{i}$ and decision $d_{i}$, and is irrelevant to states before stage $i$.
(4) Strategies: Represent a decision sequence. Strategies utilized the most during multistep decision process are the strategies of overall procedure and sub-procedure. Overall procedure refers to the process from the original state to the end state of stage 1 , whereas sub-procedure $k$ refers to the process from the original state to the end state of stage $k$.

The strategies of overall procedure and sub-procedure $k$ are:

$$
\begin{aligned}
\mathrm{P}_{1, N} & =\left\{d_{1}\left(s_{1}\right), d_{2}\left(s_{2}\right), \cdots, d_{N}\left(s_{N}\right)\right\} \\
\mathrm{P}_{k, N} & =\left\{d_{k}\left(s_{k}\right), \cdots, d_{N}\left(s_{N}\right)\right\}
\end{aligned}
$$

(5) Stage Indicator Function: Serves as the evaluation indicator for profits gained through the transfer from decision $d_{i}$ at original state $S_{i}$ to $S_{i+1}$. Stage indicator function is the function of state and decision, which is represented as:

$$
r_{i}=r_{i}\left(s_{i}, d_{i}\right)
$$

Corresponding stage indicator functions of the overall procedure and sub-procedure are $R_{1, N}$ and $R_{k, N}$, which are the functions of the original state and the strategy:

$$
\begin{aligned}
& R_{1, N}=\sum_{i=1}^{N} r_{i}\left(s_{i}, d_{i}\right)=R\left(s_{1}, P_{1, N}\right) \\
& R_{k, N}=\sum_{i=k}^{N} r_{i}\left(s_{i}, d_{i}\right)=R\left(s_{k 1}, P_{k, N}\right)
\end{aligned}
$$

(6) Target Function of Multistep Decision Process: Marks the optimal value of the indicator function of the overall procedure, i.e. the functional value of the overall procedure under optimal strategy:

$R^{*}=\operatorname{opt} R\left(s_{1}, P_{1, N}\right)=R\left(s_{1}, P^{*}\right)$

(7) Multistep Decision Process: Process from systematic original state $S_{1}$ to end state $S_{N+1}$ after a series of state transformation, which is divided into $\mathrm{N}$ stages: decision $d_{i}$ made during state $S_{i}$ at state $i$ renders effective after the systematic transfer to $S_{i+1}$. Multistep decision process is to make decisions stage by stage during the entire process to gain the optimal strategy and arrive at the optimal value $R^{*}$ of the system indicator function $R_{1, N}$.

\subsection{Basic Steps of Dynamic Optimization:}

Designing an algorithm of standard dynamic optimization usually follows such steps:

(1) Divide stages: Problems should be divided into several stages based on their temporal or spatial qualities. It should be noted that such stages should be sequential or subject to orderly arrangement (i.e. without backward tendency), otherwise the problems cannot be solved through dynamic designing. 
(2) Select states: Objective conditions at which problems are supposed to arrive during various stages should be marked as different states. Of course, the selection of the states should leave no aftereffects.

(3) Determine the strategy and come up with the state transfer function: Since decisions and state transfers are naturally correlated, state transfer is supposed to reduce the state of the current stage based on the states and decisions of the last stage. The state transfer function hence would come out naturally once the decisions are made. However in practice, counter decisions are made based on the relationship among states of neighboring stages.

(4) Write out the optimization function (including boundary conditions): Basic functions of dynamic optimization are the general expressive form of optimization functions.

\subsection{General Forms of Dynamic Optimization Models:}

Dynamic optimization model consists of three parts: target function, the constraint conditions and systematic functions to be met by stage states and decisions, and the systematic function, which is marked as:

Target function:

optR $=\sum_{i=1}^{N} r_{i}\left(s_{i}, d_{i}\right)$

The constraint conditions:

$s_{i} \in S_{i}, d_{i}\left(s_{i}\right) \in D_{i}\left(s_{i}\right), i=1,2, \cdots, N$

The systematic function:

$s_{i+1} \in T_{i}\left(s_{i}, d_{i}\right), i=1,2, \cdots, N$

\section{OPTIMAL REGIONAL ANNUAL WATER} ALLOCATION MODEL

\subsection{Dynamic Optimization Process:}

Establish an optimal allocation model of annual regional water to distribute regional available water supply into civic living, farm irrigation, forestry, animal husbandry, livestock, fishery, industry, urban public, and ecologically environmental usages [17-19]. Water quota under each project will then be assigned to various sub-sectors. The optimal structure and system of annual regional water allocation is shown below in Fig. (1).

\subsection{Structure and System of Optimal Annual Regional Water Allocation:}

(1) Stage Variables: Regional water is divided into six categories, including domestic usage, farm irrigation, forestry, animal husbandry, livestock, fishery, industry, urban public usage and ecologically environmental usages, with each one liable to be taken as a stage, therefore the stage variables are marked as $k=1,2, \cdots, 6$;

(2) Decision Variables: Annual water consumption of category $k$ is represented as $W_{k}^{\prime}$;

(3) State Variables: The amount of water available for allocation to current and future stages of water users, represented as $q_{k}^{\prime}$;

(4) State Transfer Function: Based on the relationship between decision variables and state variables, the state transfer function is represented as $q_{k+1}^{\prime}=q_{k}^{\prime}-W_{k}^{\prime}$;

(5) Indicator Function: Indicator function of stage $k$ is referred to as the usage benefit of water category $k$;

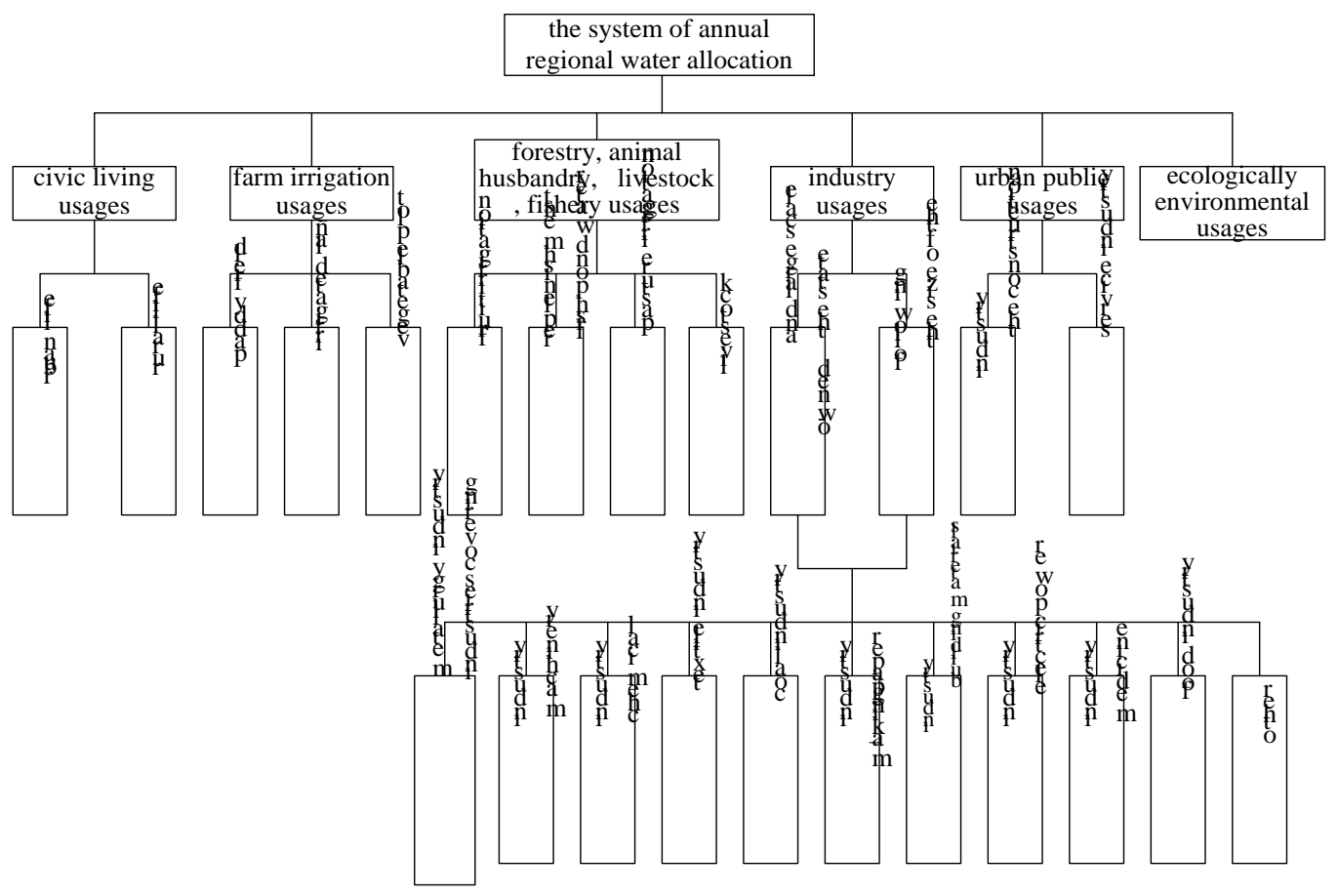

Fig. (1). Regional Annual water allocation optimization architecture. 
(6) Target Function: Aimed at the maximum sum of all net benefit gained from water consumption of all categories, and the minimum sum of the corresponding variance of simulated and actual water consumption to distribute the total amount of water into regional living, farm irrigation, forestry, animal husbandry, livestock, fishery, industry, urban public and ecologically environmental usages, corresponding target functions are:

$B\left(W^{\prime}\right)=\max \sum_{k=1}^{6} B_{k}\left(W_{k}^{\prime}\right)$

$T=\min \sum_{k=1}^{6}\left(W_{k}-W_{k}^{\prime}\right)^{2}$

Where, $B\left(W^{\prime}\right)$ is maximum annual profit (hundred billion RMB) gained from regulated amount of water based on the regional annual plan; $W_{k}^{\prime}$ is regional annual stimulated water consumption under category $k$, measured in hundred million $\mathrm{m}^{3} ; W_{k}$ is regional annual actual water consumption under category $k$, measured in hundred million $\mathrm{m}^{3} ; B_{k}\left(W_{k}^{\prime}\right)$ is net benefits obtained in category water $k$, hundred million RMB, $k=1,2, \cdots, 6$, refers to water usages in regional living, farm irrigation, forestry, animal husbandry, fishery, industry, urban public and ecologically environmental usages; $T$ is minimum sum of the variance of simulated and actual water consumption.

(7) Constraints

Approved annual water consumption constraints:

$W^{\prime}=\sum_{k=1}^{6} W_{k}^{\prime}$

Regional water balance:

Upper and lower bound:

$W_{k, \min }^{\prime} \leq W_{k}^{\prime}(t) \leq W_{k, \max }^{\prime}$

Restriction to the available amount of water during certain periods:

$W^{\prime} \leq W_{t}^{\prime}$

Variable non-negative constraints:

$W_{k}^{\prime}(t) \geq 0$

Where, $W_{k, \min }^{\prime}$ represents the planned amount of water basically meeting the minimum need of water under category $k$, ten thousand $\mathrm{m}^{3} ; W_{k, \max }^{\prime}$ represents planned amount water meeting the maximum need of water under category $k$, ten thousand $\mathrm{m}^{3} ; W_{t}^{\prime}$ represents the available amount of water during period $t$, ten thousand $\mathrm{m}^{3}$.

Reversed order method can be used to solve the above model, the basic function is:

$$
f_{k}^{*}\left(q_{k}^{\prime}\right)=\max \left\{\begin{array}{l}
g_{k}\left(W_{k}^{\prime}\right)+f^{*}{ }_{k+1}\left(q^{\prime}-W_{k}^{\prime}\right), k=1,2, \cdots 5 \\
g_{k}\left(W_{k}^{\prime}\right), k=6
\end{array}\right.
$$

Initial conditions: Water available for distribution in the first phase is no more than the total amount of water.

\subsection{Benefit Function:}

\section{(1) Industrial Water}

Water using efficiency computation adopts net output allocation method. The equation is represented as the following:

$$
B_{2}\left(W_{2}^{\prime}\right)=\beta \cdot(Q / W)
$$

Where, $\beta$ represents the benefit-sharing factor for industrial water, according to the research findings by Water Economy, generally the preferable number is $11 \%$; $Q$ is the industrial distribution of water, $\mathrm{m}^{3} ; \mathrm{W}$ is the industrial water consumption of ten thousand RMB output value, marked as $\mathrm{m}^{3} /$ ten thousand RMB.

\section{(2) Domestic Water}

Taking efficiency generated through per cubic meter of industrial water as a reference, domestic water allocation accounts for different proportions of water, take a different scaling factor, multiplied by the per cubic meter of industrial water efficiency, the total benefits is calculated. Throughout the period, benefits of no more than $80 \%$ of the required amount of water per cubic meter are $\eta_{1}-1$ times higher than benefits gained by industrial water (including above and under scaled industries) per cubic meter. Benefits of over $80 \%$ of the required amount (but less than the required amount of living water demand) per cubic meter are considered as equal to the efficiency of industrial water per cubic meter, efficiency for the amount above the required demand of living water is marked as zero per cubic meter.

$$
B_{1}\left(W_{1}^{\prime}\right)=\left\{\begin{array}{l}
\eta_{1} B_{0} Q_{s}, 0 \leq Q_{s} \leq Q_{s . \text { mas }} \\
\eta_{1} B_{0}\left(80 \% Q_{s . \max }\right)+B_{0}\left(Q_{s . \max }-80 \% Q_{s . \max }\right), \\
80 \% Q_{s . \max } \leq Q_{s} \leq Q_{s . \text { mas }} \\
\eta_{1} B_{0}\left(80 \% Q_{s . \max }\right)+B_{0}\left(Q_{s . \max }-80 \% Q_{s . \max }\right), \\
Q_{s} \geq Q_{s . \text { mas }}
\end{array}\right.
$$

Where, $Q_{s}$ is the actual allocation of living water; $Q_{\text {s.max }}$ is demand for domestic water; $B_{0}$ is the benefits of industrial water per cubic meter. $\boldsymbol{B}_{\mathbf{0}}=\boldsymbol{\beta} / \boldsymbol{W}(\boldsymbol{\beta}, W$ refer to the sharing value of industrial water benefits coefficient and water consumption of the industrial output of ten thousand RMB); $\eta_{1}$ is the ratio of living water benefits and industrial water benefits per cubic meter, the coefficient is determined as above 1 before living water meets the designing need, $\eta_{1}$ is determined as 1.8 when water supply does not reach $80 \%$ of the demanded amount of domestic water.

\section{(3) Urban Public Water}

Within $80 \%$ of the annual water demand, water benefits is $\eta_{2}-1$ times higher than industrial benefits per cubic meter, benefits of the amount above the $80 \%$ line (but less than the demanded amount of urban public water) are considered as equal to benefits of the industrial water. Benefit for the amount above the required demand of living water is marked 
as zero per cubic meter. The production function is listed as follows:

$$
B_{3}\left(W_{3}^{\prime}\right)=\left\{\begin{array}{l}
\eta_{2} B_{0} Q_{h}, 0 \leq Q_{h} \leq Q_{h \text { mas }} \\
\eta_{2} B_{0}\left(80 \% Q_{h \text { max }}\right)+B_{0}\left(Q_{h \text { max }}-80 \% Q_{h \text { max }}\right), \\
80 \% Q_{h \text { max }} \leq Q_{h} \leq Q_{h \text { mas }} \\
\eta_{2} B_{0}\left(80 \% Q_{h \text { max }}\right)+B_{0}\left(Q_{h . \text { max }}-80 \% Q_{h \text { max }}\right), \\
Q_{h} \geq Q_{h \text { mas }}
\end{array}\right.
$$

where, $Q_{h}$ is the actual allocated amount of urban public water; $Q_{h \max }$ is the demand of urban public water; $\eta_{2}$ is the ratio of the benefits of urban public water per cubic meter and the benefits of industrial water per cubic meter. Coefficient is determined as above 1 when the amount of urban public water does not meet designing requirements, and $\eta_{2}$ is determined as 1.5 when the amount of water supply does not meet the $80 \%$ quota of designed water demand of urban public water.

\section{(4) Eco-environmental Water}

Eco-environmental water is the basic water to maintain regional ecological water environment, with the source usually coming from river, natural precipitation, recycled water and urban regenerated water or recycled water [20, 21]. Tap water is not utilized except for special occasions despite its high social and ecological benefits, because its direct economic efficiency is quite low. Therefore, in the process of making the calculation model, water used for the eco-environmental end is not included in the model for calculation.

\section{CASE STUDY}

In 2011, the water demand of urban life, rural life, secondary industry, tertiary industry, agriculture and ecological environment in a city totaled $2,141,890,000 \mathrm{~m}^{3}$. Whereas analysis conducted on data of the regional inflow and available water, combined with the amount of water supply from higher authorities, the designed annual amount of urban water supply was 2,002,740,000 $\mathrm{m}^{3}$. With the planned amount of regional water supply being less than the total amount of water demand, further inspection is needed to determine the exact amount of water needed by water in urban life, rural life, secondary industry and tertiary industry, agriculture and ecological environment, while optimal allocation is also required

\subsection{Optimal Allocation of Water by Category:}

In accordance with the dynamic optimal allocation model that has been mentioned above, the MATLAB software is utilized to calculate optimal allocation. Take the condition of water supply being $2,002,740,000 \mathrm{~m}^{3}$ as a constraint and maximizing benefits as a goal by optimizing the allocation of water supply, Table $\mathbf{1}$ shows the optimal water supply allocation model of each county. From Table 1, we can see that the water supply of the towns in this area is reduced by $3,860,000 \mathrm{~m}^{3}$, with the reduction rate being $1.3 \%$; water supply of villages in the countryside is reduced by $11,750,000 \mathrm{~m}^{3}$, with the reduction rate being about $10 \%$. As for water supply for secondary industries, the amount is reduced by $36,630,000 \mathrm{~m}^{3}$, with the reduction rate being $6.5 \%$. Tertiary industry's water supply is decreased by $11,680,000 \mathrm{~m}^{3}$, with the reduction rate being $3.0 \%$. Water supply for agriculture is decreased by $74,400,000 \mathrm{~m}^{3}$, with the reduction rate being $9.0 \%$. Water supply for ecoenvironment is decreased by $10,830,000 \mathrm{~m}^{3}$, with the reduction rate being $4.0 \%$.

\subsection{Optimal Allocation of Water by Category:}

According to statistics on urban water usage, this project is determined to study the water consumption of industries covering metallurgy industry, machinery industry, chemical industry, textile industry, building materials industry, medicine industry, coal industry, electric power industry, paper-making industry and food industry. These ten industries consume over $90 \%$ of the entire amount of urban

Table 1. The outcome of optimal allocation of regional water among counties $10,000 \mathbf{~ m}^{3}$.

\begin{tabular}{|c|c|c|c|c|c|c|c|c|c|c|c|c|}
\hline Partition & \multicolumn{2}{|c|}{ Urban Life } & \multicolumn{2}{|c|}{ Rural Life } & \multicolumn{2}{|c|}{ Secondary Industry } & \multicolumn{2}{|c|}{ Tertiary Industry } & \multicolumn{2}{|c|}{ Agriculture } & \multicolumn{2}{|c|}{$\begin{array}{c}\text { Ecological } \\
\text { Environment }\end{array}$} \\
\hline 1zone & 1757 & 1722 & 1523 & 1371 & 10681 & 9933 & 74 & 72 & 3076 & 2799 & 74 & 70 \\
\hline 2zone & 1072 & 1051 & 1134 & 1021 & 4830 & 4492 & 216 & 210 & 2027 & 1845 & 107 & 102 \\
\hline 3zone & 1225 & 1201 & 1324 & 1192 & 5732 & 5331 & 312 & 303 & 11497 & 10462 & 36 & 34 \\
\hline 5zone & 329 & 322 & 127 & 114 & 1956 & 1819 & 57 & 55 & 682 & 621 & 10 & 10 \\
\hline 6zone & 1513 & 1483 & 1486 & 1337 & 6206 & 5772 & 267 & 259 & 2644 & 2406 & 86 & 82 \\
\hline 7zone & 21743 & 21526 & 2233 & 2010 & 15057 & 14304 & 3793 & 3717 & 13672 & 12305 & 25872 & 24837 \\
\hline 8zone & 1107 & 1096 & 1082 & 974 & 5344 & 4970 & 383 & 372 & 3699 & 3366 & 259 & 246 \\
\hline
\end{tabular}


water usage. However, different conditions may apply to different cities, therefore further adjustment needs to be applied to the specific industrial structure and characteristics of a city. In this case, we only formulate optimal water allocation model based on water consumption of such ten industries.

Build an optimal allocation model of water supply for every county and every industry and allocate the water yield to different industries in accordance with the water supply plan.

(1) Water Consumption Structure of Industrial Sectors

Water consumption structure of industrial sectors is formulated as below:

$$
\begin{aligned}
& W_{1,2}(t)=F_{1,2}\left\{\begin{array}{l}
W_{1,2,1}(t), W_{1,2,2}(t), W_{1,2,3}(t), W_{1,2,4}(t), W_{1,2,5}(t), \\
W_{1,2,6}(t), W_{1,2,7}(t), W_{1,2,8}(t), W_{1,2,9}(t), W_{1,2,10}(t)
\end{array}\right\} \\
& W_{1,2, i, \min } \leq W_{1,2, i}(t) \leq W_{1,2, i, \max } \quad i=1,2, \cdots, 10
\end{aligned}
$$

where, $W_{1,2,1}(t)$ is metallurgical industry planning water supply in certain period $t, 10,000 \mathrm{~m}^{3} ; W_{1,2,2}(t)$ is machinery industry planning water supply in certain period $t, 10,000$ $\mathrm{m}^{3} ; W_{1,2,3}(t)$ is chemical industry planning water supply in certain period $t, 10,000 \mathrm{~m}^{3} ; W_{1,2,4}(t)$ is textile industry planning water supply in certain period $t, 10,000 \mathrm{~m}^{3}$; $W_{1,2,5}(t)$ is building materials industry planning water supply in certain period $t, 10,000 \mathrm{~m}^{3} ; W_{1,2,6}(t)$ is medicine industry planning water supply in certain period $t, 10,000 \mathrm{~m}^{3}$; $W_{1,2,7}(t)$ is electric power industry planning water supply in certain period $t, 10,000 \mathrm{~m}^{3} ; W_{1,2,8}(t)$ is paper-making industry planning water supply in certain period $t, 10,000$ $\mathrm{m}^{3} ; W_{1,2,9}(t)$ is food industry planning water supply in certain period $t, 10,000 \mathrm{~m}^{3} ; W_{1,2,10}(t)$ is coal industry planning water supply in certain period $t, 10,000 \mathrm{~m}^{3} ; W_{1,2, i, \min }$ is meet the basic demand of water supply made to satisfy the scale of production for the secondary industries, $10,000 \mathrm{~m}^{3}$; $W_{1,2, i, \max }$ is meet the maximum demand of water supply plan made to satisfy the scale of production for the secondary industries in certain period $t, 10,000 \mathrm{~m}^{3}$.

(2) Optimal Water Allocation for Each Urban Industry

1) Optimal allocation

Adopt the optimal allocation model to allocate water supply for different industries in the city. Assume the planned water supply yield is $Q$, and the water demand of different unit $V_{j}(j=1,2, \cdots n)$ is $q_{j}$, the total water demand is:

$$
Q_{0}=\sum_{j=1}^{n} q_{j}
$$

The profit function of the allocated water yield $V_{j}$ towards $X_{j}$ is $f\left(x_{j}\right)$, then:
Target function:

$\operatorname{Max} f\left(x_{j}\right)=f\left(x_{1}\right)+f\left(x_{2}\right)+\cdots f\left(x_{n}\right)$

The constraint conditions:

$x_{1}+x_{2}+\cdots x_{n}=Q$;

$q_{\min } \leq x_{j} \leq q_{j}(j=1,2, \cdots n)$

Among them, $f\left(x_{j}\right)=x_{j} \times P_{j}(j=1,2, \cdots n), P_{j}$ represents the $j$ industry million Yuan RMB output value of water.

\section{2) Determination of the Parameter}

Profit function adopts ten thousand RMB output value methods to calculate the result. Relevant water consumption data in ten thousand RMB output value methods are cited from the city statistical yearbook.

\section{3) Industrial Water Allocation}

One city's allocated water yield for industrial uses is $529,670,000 \mathrm{~m}^{3}$, which includes metallurgy industry $\left(101,930,000 \mathrm{~m}^{3}\right)$, machinery industry $\left(56,630,000 \mathrm{~m}^{3}\right)$, chemical industry $\left(45,300,000 \mathrm{~m}^{3}\right)$, textile industry $\left(16,990,000 \mathrm{~m}^{3}\right)$, building materials industry $(67,960,000$ $\left.\mathrm{m}^{3}\right)$, medicine industry $\left(39,640,000 \mathrm{~m}^{3}\right)$, coal industry $\left(113,260,000 \mathrm{~m}^{3}\right)$, electric power industry $\left(22,650,000 \mathrm{~m}^{3}\right)$, paper-making industry $\left(67,960,000 \mathrm{~m}^{3}\right)$ and food industry $\left(33,980,000 \mathrm{~m}^{3}\right)$. The total water yield demand in all industries is $566,300,000 \mathrm{~m}^{3}$. Each of the profit function is $f\left(x_{j}\right)=x_{j} \times P_{j}(j=1,2, \cdots n)$. Use the optimal allocation model mentioned above and put the relevant data into the model, we should arrive at:

Target function: $\operatorname{Max} f\left(x_{j}\right)=f\left(x_{1}\right)+f\left(x_{2}\right)+\cdots f\left(x_{n}\right)$

The constraint conditions:

$$
\begin{aligned}
& x_{1}+x_{2}+\cdots x_{n}=52967 \\
& 9600 \leq X_{1} \leq 10193 ; 5102 \leq X_{2} \leq 5663 \\
& 4050 \leq X_{3} \leq 4530 ; 1430 \leq x_{4} \leq 1699 \\
& 5780 \leq{ }^{X_{5}} \leq 6796 ; 3580 \leq x_{6} \leq 3964 \\
& 11050 \leq{ }^{X_{7}} \leq 11326 ; 1980 \leq{ }^{X_{8}} \leq 2265 \\
& 6200 \leq x_{9} \leq 6796 ; 3260 \leq X_{10} \leq 3398
\end{aligned}
$$

Use the model to solve out the result (shown in Table 2). From Table $\mathbf{2}$ we can see, the allocated water yield for metallurgy industry, machinery industry, chemical industry, textile industry, building materials industry, medicine industry, coal industry, electric power industry, papermaking industry and food industry are $100,870,000 \mathrm{~m}^{3}$, $51,310,000 \mathrm{~m}^{3}, 41,460,000 \mathrm{~m}^{3}, 14,300,000 \mathrm{~m}^{3}, 58,940,000$ $\mathrm{m}^{3}, \quad 36,010,000 \mathrm{~m}^{3}, \quad 111,560,000 \mathrm{~m}^{3}, 19,820,000 \mathrm{~m}^{3}$, $62,360,000 \mathrm{~m}^{3}$ and $33,040,000 \mathrm{~m}^{3}$. Since different industry has different industrial structure, the water demand of industrial production and allocated water yield also vary. The industrial zone's total water consumption is reduced by 
Table 2. Result of allocated water yield for industries $10,000 \mathrm{~m}^{3}$.

\begin{tabular}{|c|c|c|c|c|c|c|c|c|c|c|c|c|}
\hline \multirow{2}{*}{ Partition } & \multicolumn{2}{|c|}{ Urban Life } & \multicolumn{2}{|c|}{ Rural Life } & \multicolumn{2}{|c|}{ Secondary Industry } & \multicolumn{2}{|c|}{ Tertiary Industry } & \multicolumn{2}{c|}{ Agriculture } \\
\cline { 2 - 13 } & $\begin{array}{c}\text { Water } \\
\text { Demand }\end{array}$ & $\begin{array}{c}\text { Plan of } \\
\text { Water } \\
\text { Supply }\end{array}$ & $\begin{array}{c}\text { Water } \\
\text { Demand }\end{array}$ & $\begin{array}{c}\text { Plan of } \\
\text { Water } \\
\text { Supply }\end{array}$ & $\begin{array}{c}\text { Water } \\
\text { Demand }\end{array}$ & $\begin{array}{c}\text { Plan of } \\
\text { Water } \\
\text { Supply }\end{array}$ & $\begin{array}{c}\text { Water } \\
\text { Demand }\end{array}$ & $\begin{array}{c}\text { Plan of } \\
\text { Water } \\
\text { Supply }\end{array}$ & $\begin{array}{c}\text { Water } \\
\text { Demand }\end{array}$ & $\begin{array}{c}\text { Plan of } \\
\text { Water } \\
\text { Supply }\end{array}$ & $\begin{array}{c}\text { Water } \\
\text { Demand } \\
\text { Plan of } \\
\text { Water } \\
\text { Supply }\end{array}$ \\
\hline \hline 1zone & 1757 & 1722 & 1523 & 1371 & 10681 & 9933 & 74 & 72 & 3076 & 2799 & 74 & 70 \\
\hline 2zone & 1072 & 1051 & 1134 & 1021 & 4830 & 4492 & 216 & 210 & 2027 & 1845 & 107 & 102 \\
\hline 3zone & 1225 & 1201 & 1324 & 1192 & 5732 & 5331 & 312 & 303 & 11497 & 10462 & 36 & 34 \\
\hline 4zone & 896 & 878 & 1197 & 1077 & 3776 & 3512 & 255 & 247 & 10815 & 9842 & 26 & 25 \\
\hline 5zone & 329 & 322 & 127 & 114 & 1956 & 1819 & 57 & 55 & 682 & 621 & 10 & 10 \\
\hline 6zone & 1513 & 1483 & 1486 & 1337 & 6206 & 5772 & 267 & 259 & 2644 & 2406 & 86 & 82 \\
\hline 7zone & 21743 & 21526 & 2233 & 2010 & 15057 & 14304 & 3793 & 3717 & 13672 & 12305 & 25872 & 24837 \\
\hline 8zone & 1107 & 1096 & 1082 & 974 & 5344 & 4970 & 383 & 372 & 3699 & 3366 & 259 & 246 \\
\hline 9zone & 1067 & 1046 & 1646 & 1481 & 3048 & 2835 & 238 & 231 & 34552 & 31442 & 369 & 351 \\
\hline total & 30709 & 30323 & 11752 & 10577 & 56630 & 52967 & 5595 & 5427 & 82664 & 75224 & 26839 & 25756 \\
\hline
\end{tabular}

$36,630,000 \mathrm{~m}^{3}, 6.47 \%$. In terms of total consumption, metallurgy industry has the smallest reduction, only $1.04 \%$. Textile industry has the largest reduction, 15.83\%. Based on this optimal model to simulate water supply allocation for every industry, the basic idea of the water demand and water consumption is prevalent in industries. The simulation result hence is quite sound.

\section{CONCLUSIONS}

When regional annual water demand is larger than the available water supply or the limited amount by the government, every region and industry lacks concrete evidence to decrease its water yield. It would be easy to neglect the different trait and water usage efficiency of every industry. Studying an optimal allocation model of water can help solve this problem better. Given the controlled total water consumption and the concept, theory, and calculation steps of optimal allocation of annual regional water, we aim to optimize the total regional water usage efficiency. With the limitation of the total regional water yield, we build an optimal dynamic annual water allocation model among regions. Through this optimal allocation model we adjust a city's plan to water consumption in areas such as domestic water, water for agricultural irrigation, water for forestry, animal husbandry, public facilities, environment and different industries. The result shows that this model can allocate and reduce water consumption of every water user. It's suitable to apply this model to optimize allocation of annual regional water.

\section{CONFLICT OF INTEREST}

The author confirms that this article content has no conflicts of interest.

\section{ACKNOWLEDGMENTS}

This work is financially supported by NSFC-Henan Provincial People's Government Joint Fund of Personnel Training (No.U1304511), Henan Provincial Natural Science Foundation (No.132300410020, No.112300410035), “948” Project of Ministry of Water Resources (No.2013028), Zhengzhou Scientific and Technological Project (No.121 PPTGG358, No.131PPTGG410), Collaborative Innovation Center of Water Resources Efficient Utilization and Protection Engineering, Henan Province, Program for Science \& Technology Innovation Talents in Universities of Henan Province(No.15HASTIT049), and Program for Innovative Research Team (in Science and Technology) in University of Henan Province (No.14IRTSTHN028). Our gratitude is also extended to reviewers for their efforts in reviewing the manuscript and their very encouraging, insightful and constructive comments.

\section{REFERENCES}

[1] B. He, "The optimums model of large scale system for optimal allocation of regional water resources", Journal of Wuhan Institute of Water Conservancy and Electric Power, vol. 5, pp. 109-118, 1988.

[2] G. Wang, and J. Wei, Model and Application of River Basin Water Resources Regulation. Beijing: Science Press, 2006, pp.17-21.

[3] Y. Feng, H. Xiu, and H. Wang, "Optimal allocation of regional water resources research for sustainable development”, Systems Engineering Theory and Practice, vol. 2, pp. 133-138, 2003.

[4] L. Zhang, and L. Gao, "Study on optimal allocation of regional water resources under constraint of multi-objective", Journal of Water Resources and Water Engineering, vol. 4, pp. 16-19, 2014.

[5] Y. Li, "Basic functions of the reasonable allocation of water resources management in the implementation of the most rigorous system”, China Water Conservancy, vol. 20, pp. 26-28, 2010.

[6] L. Giang, and B. Zhao, "Application of dynamic in water resources allocation”, Yellow River, vol. 30, no. 5, pp. 47-48, 2008.

[7] Z. Sun, S. Xia, and D. Xu, "Regional water resources optimal allocation model”, Journal of Zhejiang University, vol. 43, no. 2, pp. 344-348, 2009. 
[8] A. Singh, and S. N. Panda, "Optimization and simulation modelling for managing the problems of water resources", Water Resources Management, vol. 27, no. 9, pp. 3421-3431, 2013.

[9] Y. Han, Y. F. Huang, and G. Q. Wang, "A multi-objective linear programming model with interval parameters for water resources allocation in Dalian”, City Water Resources Management, vol. 25, no. 2, pp. 449-463, 2011.

[10] D. P. Louck, "Sustainable water resources management", Journal of Water Resources Planning and Management, vol. 126, no. 2, pp. 43-47, 2000.

[11] J. B. Braden, and E. G. Vanlerland, "Balancing the economic approach to sustainable water management", Water Science and Technology, vol. 39, no. 5, pp. 17- 23, 1999.

[12] H. Wang, J. Wang, and D. Qin, "Research advance and direction on the theory and practice of reasonab1e water resources allocation”, Advances in Water Science, vol. 15, no. 1, pp. 123-128, 2004.

[13] D. G. Jameison, and K. Fedra, "The water ware decision support design for river basin planning conceptual design”, Hydrology, vol. 177, pp. 163-175, 1996.

[14] E. Zagona, T. Fulp, and R. Shane, "Review: a generalized tool for complex reservoir system modeling”, Water Resource, vol. 37, no. 4, pp. 913-929, 2001.

[15] J. M. Antle, and S. M. Capallo, "Physical and economic model integration for measurement of environmental impacts of agriculture chemical use”, Journal of Agricultural and Resource Economics, vol. 20, no. 3, pp. 62-68, 1991.

[16] M. B. Bayer, "A modeling method for evaluating water quality policies in non-serial river system”, Water Resources Bulletin, vol. 33, no. 6, pp. 1141-1151, 1997.

[17] A. Javaid, and N. David, "Optimization model for alternative use of different quality irrigation waters”, Journal of Irrigation and Drainage Engineering, vol. 118, no. 2, pp. 228-218, 1992.

[18] W. David, M. Kinney Jr, and D. Robust, "Optimization for incorporating risk and uncertainty in sustainable water resources planning”, International Association of Hydrological Science, vol. 231, no. 13, pp. 225- 232, 1995.

[19] E. E. Ezenwaji, R. N. C. Anyadike, and I. Nnaemeka, "Optimal allocation of public water supply to the urban sectors of Enugu, Nigeria: a linear programming approach”, Applied Water Science, vol. 41, pp. 345-356, 2014.

[20] P. Rubino, M. Catalano, R. Rana, and A. Caliandro, "Optimal allocation of the irrigation water through a non linear mathematical model”, Italian Journal of Agronomy, vol. 20, no. 12, pp. 121-130, 2011.

[21] M. D. H. Ali, and L. T. Shui, "Optimal allocation of monthly water withdrawals in reservoir systems", Water Resources Management, vol. 14, no. 35, pp. 168-176, 2001.

(c) Xianqi Zhang; Licensee Bentham Open.

This is an open access article licensed under the terms of the Creative Commons Attribution Non-Commercial License (http://creativecommons.org/licenses/ by-nc/3.0/) which permits unrestricted, non-commercial use, distribution and reproduction in any medium, provided the work is properly cited. 